\title{
Concrete containing waste rubber particles under impact loading
}

\author{
Ali SADRMOMTAZI ${ }^{1}$, Romina Zarshin ZANOOSH ${ }^{2, *}$ \\ ${ }^{1}$ Associate professor /Faculty of engineering, University of Guilan, Rasht, Iran. \\ ${ }^{2} \mathrm{PhD}$ student of civil-Structure engineering, Faculty of engineering, \\ University of Guilan, Rasht, Iran
}

\begin{abstract}
The main objective of this study is investigate of behavior of concrete containing waste tire rubber against impact loads. Impact is one of the dynamic loads that may be occurs at high velocity and exposed concrete structures, such as the military situation. Properties of concrete containing three different sizes of rubber particles $0-1,1-3$ and $3-5 \mathrm{~mm}$ that replaced of $0 \%$, $10 \%, 20 \%, 30 \%, 40 \%$ and $50 \%$ of fine aggregate were determined. Analyses were included compressive and flexural strength, dry unit weight, velocity of ultrasonic wave and scanning of electron microscopy (SEM). For ductility of this kind of concrete, impact test done with gas gun device on it and failure such as penetration depth and average crater diameter determined too. The results indicated that when rubber particles added to concrete mixture, fracture of concrete was softer than normal concrete and concrete containing optimum size and percent of rubber particles has best properties and less failure.
\end{abstract}

Keywords: Concrete containing rubber, Impact test, Gas gun, Penetration depth, Crater diameter

\section{Introduction}

Civil engineering structures may be subjected to impact loading during their service life. Impact loading is mostly extreme loading cases with a very low probability of occurrence during lifetime of structure. Dynamic loading on concrete structures is occurring in military conditions such as missile impact, blast wave or accident conditions such as rock fall on concrete shelter, vehicles collision, aircraft impact on nuclear containment [1, 2]. Concrete with high impact resistance is highly expected for construction materials such as aircraft runway, highway pavement, bridge deck, and engineering structures. It is generally agreed that the most significant property needed by a material subjected to impact loading is its energy absorbing capability or toughness .It is also generally agreed that adding rubber to a concrete matrix leads to a significant increase in its toughness and its impact resistance [1].

The behavior of concrete structures under loading is depended on loading rate [3]. Several technique been developed to study the dynamic mechanical properties of concrete. For instance, a modified charpy impact test as in conventional charpy impact machine that used by the metallurgists, where a swinging pendulum is allowed to striker a specimen in its path there by transferring momentum. Other significant impact tests is impact test include the Split Hopkinson pressure bar test. In the specimen is sandwiched between two elastic pressure bars and stress waves are generated by a projectile [4]. Also drop-weight apparatus that has been used for impact studies of concrete beam under impact with low velocity [5, 6] and fired missile with gas- 
gun is used for impact with high velocity. The penetration depth and crater area should calculate after the impact under fire missile with gas gun $[7,8]$.

Many researches are exist about the impact behavior of concrete, but they didn't use of rubber particles in concrete mixture to make concrete more ductile. The purpose of this study is to develop concrete mixtures containing different percent of rubber particles under impact test in high velocity with gas gun device. Failure was contained of penetration depth and average crater diameter.

\section{Experiments}

\subsection{Materials}

Type I Portland cement, gravel, natural sand, water were used to prepare the concrete. In preparing the rubberized concrete samples, $10 \%, 20 \%, 30 \%, 40 \%$ and $50 \%$ by volume of fine aggregate was replaced by waste tire rubbers with sizes of $0-1 \mathrm{~mm}, 1-3 \mathrm{~mm}$ and $3-5 \mathrm{~mm}$. The cement /water ratio by weight was 0.37 . Rubber particles (Fig .1) used in this study have been obtained from mechanical shredding of rubber automobile industry waste. The absolute density of these rubber waste particles was $500 \mathrm{~kg} / \mathrm{m}^{3}$.

In this study:

$N C$ : Normal concrete

$R I$ : Concrete containing rubber particles of size $0-1 \mathrm{~mm}$.

$R I I$ : Concrete containing rubber particles of size $1-3 \mathrm{~mm}$.

RIII: Concrete containing rubber particles of size 3-5 mm.

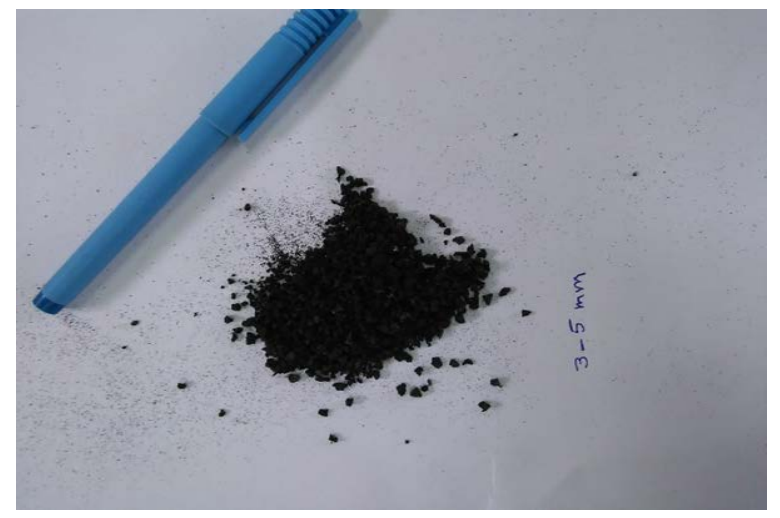

Fig. 1: Waste tire rubber particles

\subsection{Microstructure of concrete containing rubber particles}

Different kinds of microscopes are useful tools for observing and analyzing the microstructural characteristics of cement-based products. Analysis of the micro-structure of rubberized cement products has been conducted using scanning electron.

Small pieces of cement mortars or concrete have been used without any treatment in order to examine the rubber particles and cement matrix. For scanning electron microscopy, very small samples were coated with gold after having been subjected to full vacuum inside the electron microscope [9]. 
The SEM micrograph of cement composite contained of rubber particles after compressive rupture is shown in Fig.2. Rubber particles have less adhesive with cement paste and in interface zone, cracks start.

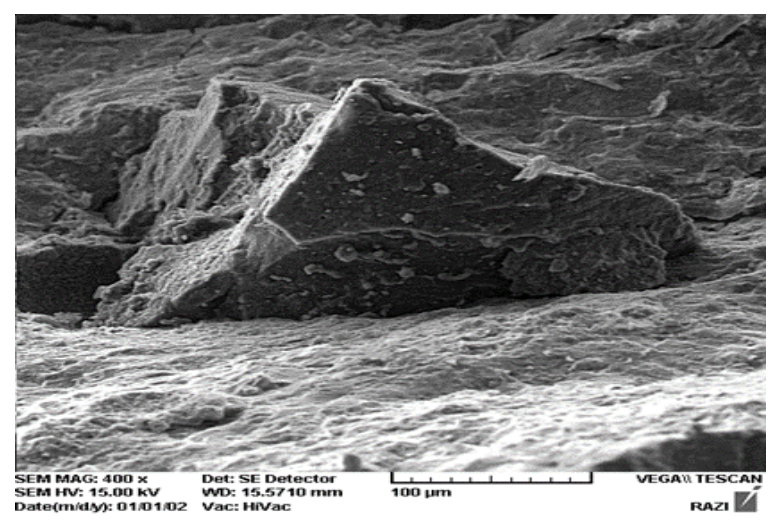

Fig. 2: SEM of waste tire rubber particles in cement composite of concrete

\subsection{Dry unit weight of concrete containing rubber particles}

The dry weight of concrete with respect to rubber volume content is displayed in Fig.3. Values decrease from normal concrete to specimen containing $50 \%$ of rubber particles. Also concrete samples containing rubber particles in range of $3-5 \mathrm{~mm}$ were lighter than other samples. The increase in rubber particle tends to heighten the level of air-entrainment. The higher air entrainment may be due to the capability of rubber particles to entrap air at their rough surface due to their no polar nature. The lightening of concrete is very attractive particularly in both building renovation works and design of lightweight structural elements [10].

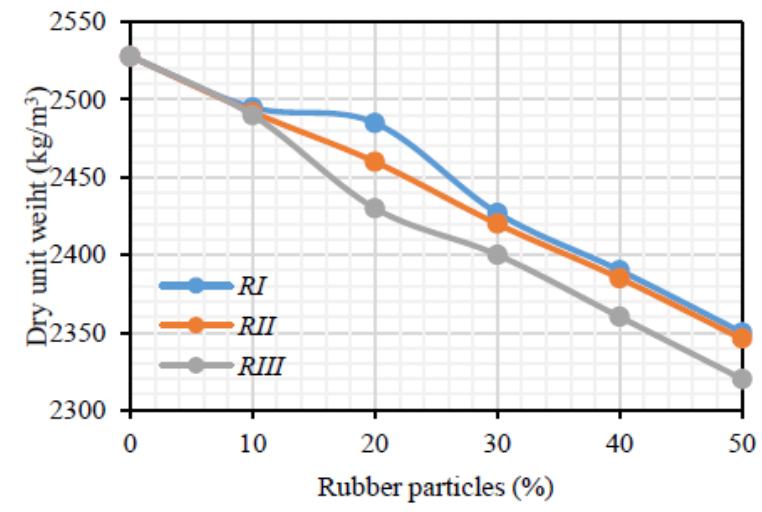

Fig. 3 Dry unit weight of concrete containing rubber particles

\subsection{Compressive Strength of concrete contained rubber particles}

As shown in Fig.4, rubberized concrete is less brittle than normal concrete. Also as shown in Fig.5, increased of rubber content, reduced compressive strength of concrete and rubber particles in size of 3-5 mm had more compressive strength than samples containing rubber particles in smaller sizes. 
The decrease in compressive strength is attributed to physical properties of rubber particles, since they are less stiff than the surrounding cement paste. Under loading, cracks are initiated around the particles, accelerating the failure in matrix. It is assumed that mechanical strength of composite is opposite to its unit weight. In addition, the decrease in compressive strength is relative to air-entrainment. When the air-voids ratio increases, it reduces the weight of the specimen and its mechanical strength.

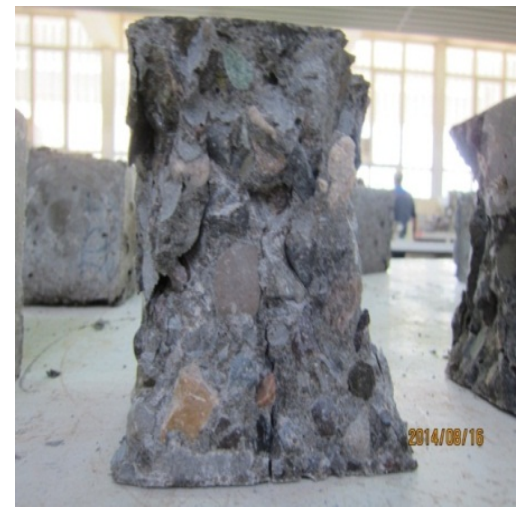

(a)

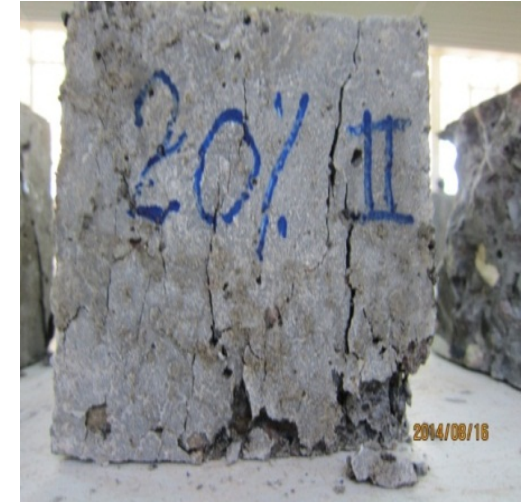

(b)

Fig. 4: Fracture of concrete after compressive test (a) Normal concrete (b) Concrete containing $20 \%$ rubber particles in size $1-3 \mathrm{~mm}$

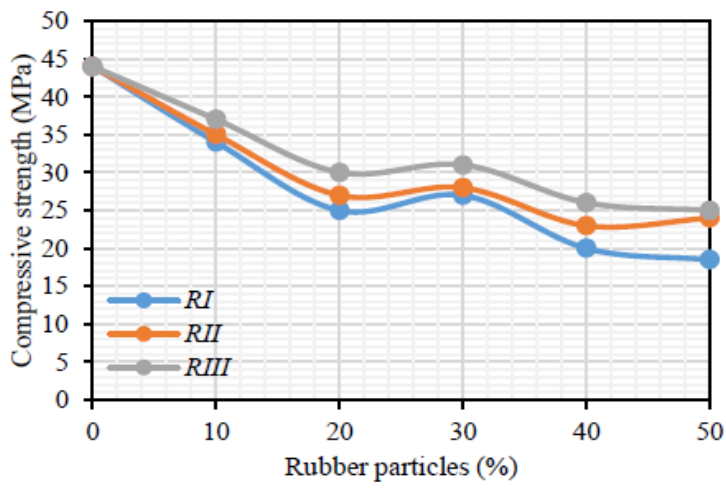

Fig. 5: Compressive strength of concrete containing rubber particles in 90 days

\subsection{Flexural strength of concrete contained rubber particles}

Flexural strength is shown in Fig.6. In flexural test, velocity of loading was $5 \mathrm{~mm} / \mathrm{s}$. With varying rubber content, the chart first shown reduction in $0 \%$ to $10 \%$ and then it shown maxima at volume ratio of $20 \%$.

The decrease in flexural strength is possibly due to reduction of the cement content in matrix and the lack of bond between rubber particles and cement paste in concrete mixture.

Also results shown that concrete containing rubber particles in size $3-5 \mathrm{~mm}$ have better resistant under flexural loading than concrete samples containing other sizes. 


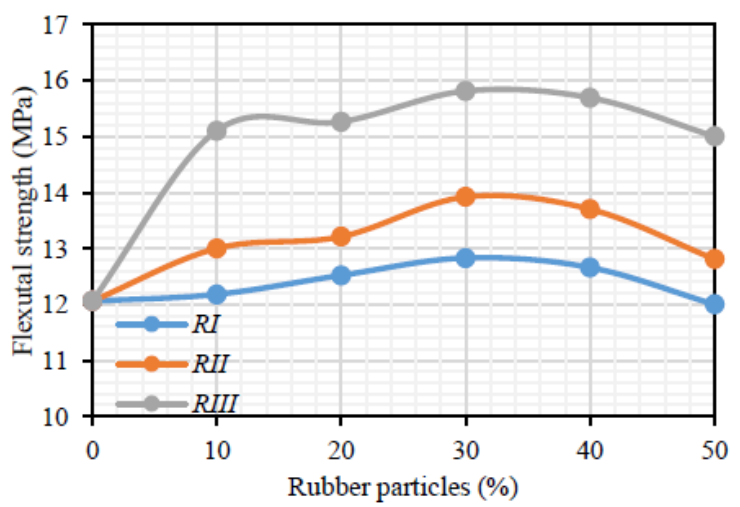

Fign6: Flexural strength of concrete containing rubber particles in 90 days

\subsection{Ultrasonic wave of concrete containing rubber particles}

The time duration for an acoustic wave to propagate through the longitudinal direction of the specimen was recorded in this study too. The ultrasonic wave bypasses air-voids in order to propagate within the concrete. Incorporation of rubber particles into cement matrix reveals the ability of composites to both reduce sound intensity and dampen vibrations, which serves to provide a high level of sound insulation [11]. As shown in Fig.7, the velocity-values decrease from $4671 \mathrm{~m} / \mathrm{s}$ of normal concrete to $3780 \mathrm{~m} / \mathrm{s}$ of concrete containing $50 \%$ of rubber particles 3$5 \mathrm{~mm}$. Also results indicate that concrete contained rubber particle in size $3-5 \mathrm{~mm}$ has better result than other samples.

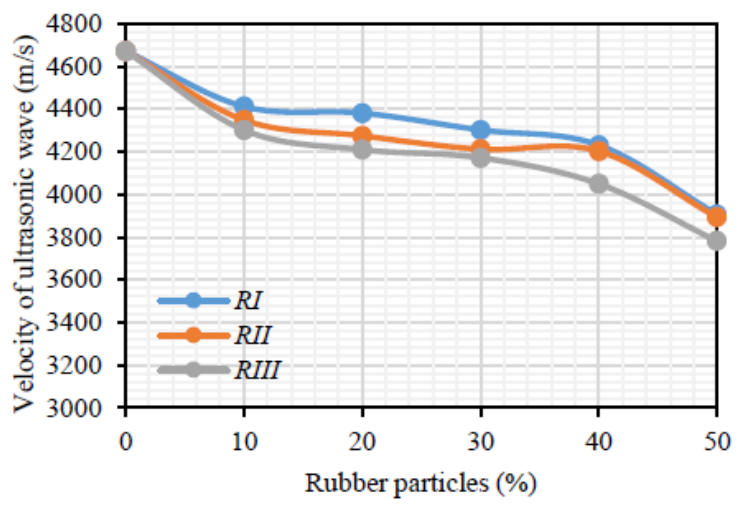

Fig 7: Velocity of ultrasonic wave for concrete containing rubber particles in 90 days

\subsection{Impact test}

As shown in Fig.8, the small projectile with 29 gr in mass and $19 \mathrm{~mm}$ in diameter was considered in impact test. The target specimens were subjected to the projectile with impact velocity in the range of $150 \mathrm{~m} / \mathrm{s}$. The impact test done with gas gun device (Fig.9). Nitrogen and Helium gases were used to accelerate the projectiles to achieve the determined velocity. The velocity of the projectile was measured by a speedometer (Fig.10) with two laser sensors. The impact velocity of the projectiles was evaluated as the distance travelled by a projectile from one laser sensor to another divided by the time which was shown on the speedometer monitor. As 
shown in Fig.15, damage of cementations targets due to high velocity impact was characterized by different failure modes, such as penetration and crater area.

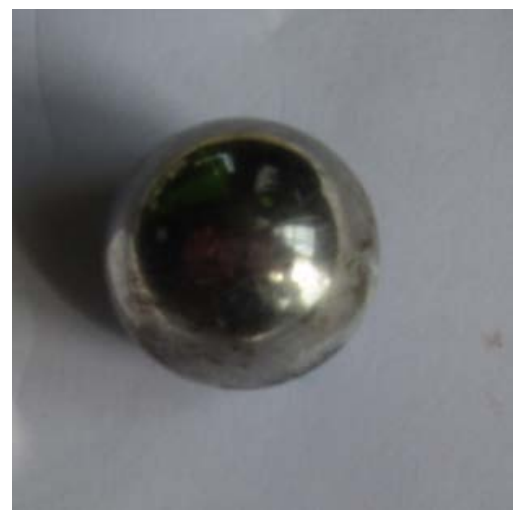

Fig. 8: The projectile with $19 \mathrm{~mm}$ diameter for impact test

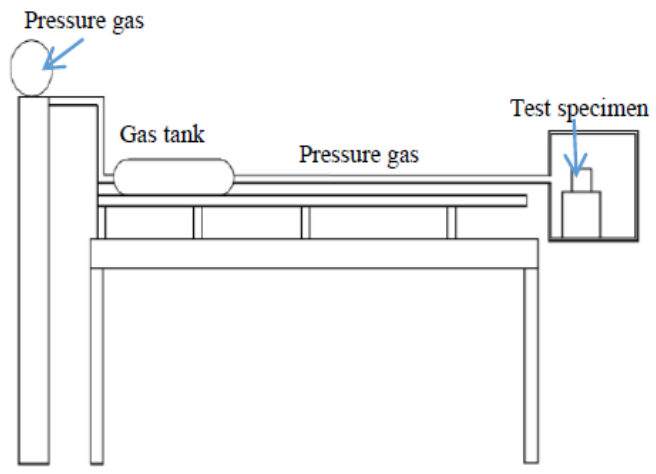

Fig. 9: Gas gun device

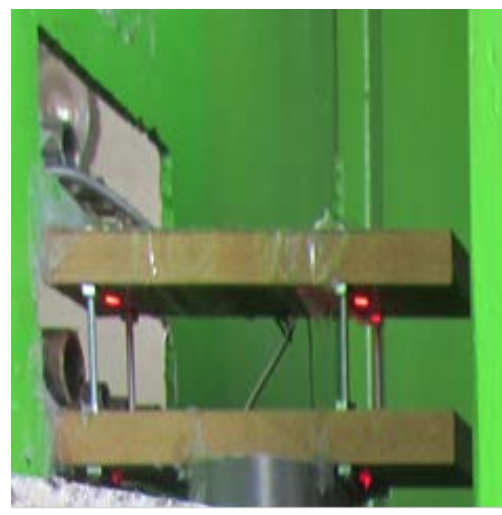

(a)

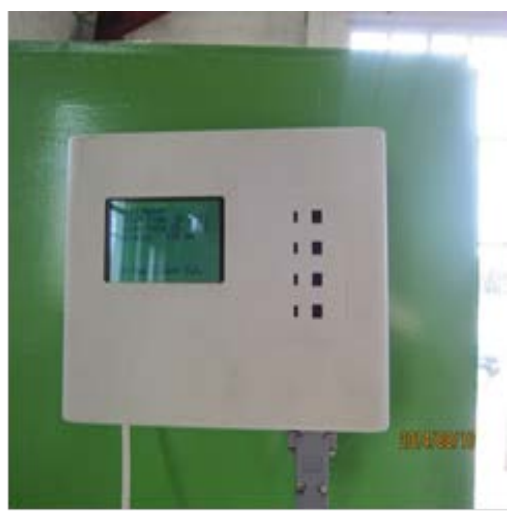

(b)

Fig 10: (a) Speedometer (b) Monitor of speedometer 


\subsubsection{Result of missile Impact test}

Damage of concrete samples contained various percent of rubber particles after impact test are shown in Fig.11. The crater diameter was determined by caliper after impact test and has been defined by Eq.(1) [12]. In this equation $D_{1}$ and $D_{2}$ are longest and shortest orthogonal dimensions of crater region. Under the impact loading, a reduced brittleness in concrete containing rubber particles was observed and as shown in Fig.12, samples containing 40\% rubber particles in size 3-5mm has smallest crater damage.

Also resulting of penetration depth under impact load is shown in Fig.13. Results indicated that when rubber particles added to concrete mixture, penetration depth decreased and rubber particles containing 30\% rubber particles 3-5mm has less penetration depth than other samples. Also failure of concrete under impact test related to compressive strength and increase in compressive strength cases decrease in penetration depth. When rubber particles added to concrete mixture, compressive strength and brittleness of concrete decreased but fracture of concrete under loading was softer than normal concrete, therefore for two concrete mixtures with same compressive strength, concrete was contained rubber particles has better ductility and less failure under impact test.

$D_{\text {eq }}=\sqrt{D_{\min } \times D_{\max }}$

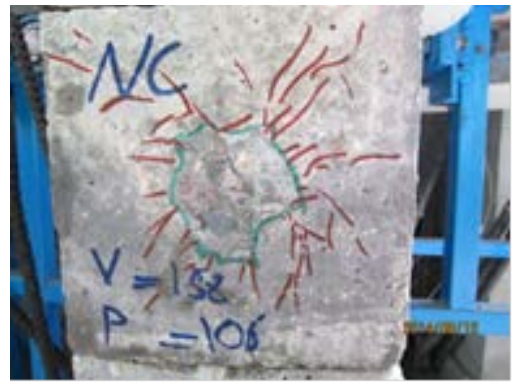

(a)

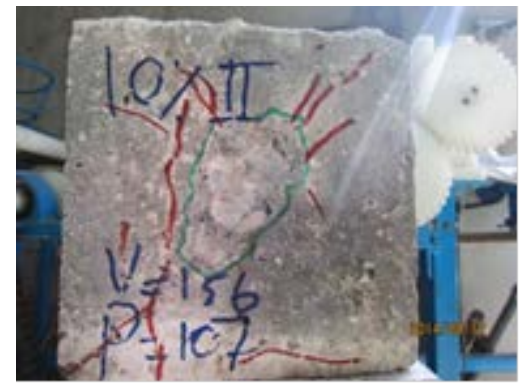

(b)

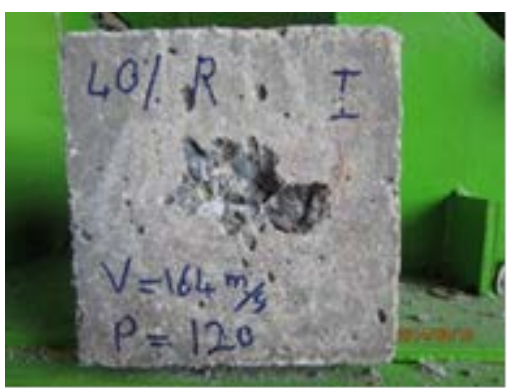

(c)

Fig. 11: Damage of concrete samples after impact test (a) Normal concrete (b) Concrete containing 10\% rubber particles (c) Concrete containing 40\% rubber particles

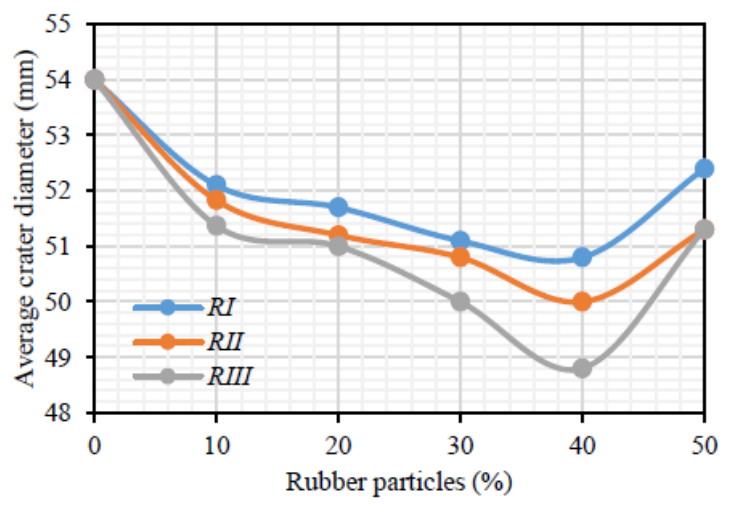

Fig. 12: Crater diameter of concrete containing rubber particles 


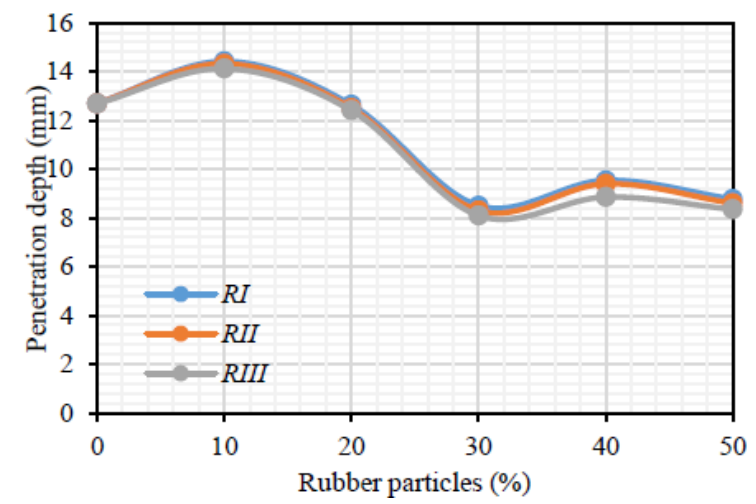

Fig. 13: Penetration depth against missile impact test

\section{Conclusions}

In this study because of physical and mechanical properties of concrete containing rubber particles, impact test considered. Impact test done with gas gun device and penetration depth and average of crater diameter determined. Results indicated that, when rubber particles added to concrete mixture compressive strength and dry unit weight and velocity of ultrasonic wave of concrete decreased, but ductility of it increased and less failure such as penetration depth and average crater diameter under impact loading observed.

This kind of concrete could be such a good material in structures that are using in shelter, breakwater, high way and etc.

\section{REFERENCES}

[1] Feng Liu and Guixuan chen. (2012). Study of impact performance of rubber reinforced concrete. Construction and building materials,vol. 36, p. 604 -616.

[2] Laurent Daudevill and Yannn Malecot. (2011).Concrete structures under impact, European journal of environmental and civil engineering, p. 101-140.

[3] Kennedy R.P. (1974) A review of procedures for the analysis and design of concrete structures to resist missle impact effect, Nuclear engineering and design,vol. 37, p. 183-200.

[4] X.Zhang and G.ruit.(2008). A new drop weight impact machine for studying fracture process in structural concrete. Analese de meccanicas fracture,vol. 25.

[5] Ian M.May and y.Chen. (2005). Experimental testing and finite element simulation of the behavior of reinforced concrete beam under impact loading, International conference on computational plasticity COMPLAS VIII.

[6] J.Y. Richard Liew, K.M.A. Sohel, and C.G. Koh. (2009). Impact tests on steel_concrete_steel sandwich beams with lightweight concrete core. Engineering Structures. vol.31, p. 2045_2059.

[7] Khin T.Soe and Y.X.Zhang. (2013). Impact resistance of hybrid-fiber engineered cementitous composite panels. Composite structure, vol 104,p.320-330.

[8] Tarek H.Almusallam and Nadeem A.Siddiqui. (2013). Response of hybrid -fiber reinforced concrete slabs to hard projectile impact, International journal of impact engineering,vol. 58, p. 17-30. 
[9] Oikonomou N., Stefaidou M , and Mavridus. (2006). .Improvement of the bonding between rubber tire particles and cement paste in cement products. in 15th conference of the technical chamber of Greece, p. 234-242.

[10] A.Sadr momtazi and R.Zarshin zanoosh. (2009). Ductile and Lightweight Cement Composite Contained Of Waste Tire Rubber. The 1st International Conference on Concrete Technology, Tabriz, Iran.

[11] Ali sadrmomtazi and Romina Zarshin Zanoosh. (2011) The effect of polypropylene fibers and rubber particles on mechanical properties of cement composite contained rise husk ash, Procedia engineering,vol. 10, p. 3608-3615.

[12] Tarek h.Almusallam and Nadeem A.(2013). Response of hybrid-fiber reinforced concrete slabs to hard projectile impact. International jurnal of mpact engineering, p. 17-30. 